\title{
SUINOCULTURA NO ESTADO DE GOIÁS: APLICAÇÃO DE UM MODELO DE LOCALIZAÇÃO
}

\author{
Ricardo Luis Lopes \\ Depto de Economia \\ Universidade Estadual de Maringá \\ e-mail: rllopes@uem.br \\ José Vicente Caixeta Filho \\ Depto de Economia, Adm. e Sociologia \\ ESALQ - USP \\ e-mail: jvcaixet@carpa.ciagri.usp.br
}

\begin{abstract}
Resumo
Esta pesquisa teve como principal objetivo a análise da distribuição mais eficiente de granjas suinícolas no Estado de Goiás. O modelo de localização desenvolvido envolveu uma estrutura de programação inteira mista. Os fatores considerados para o objetivo do estudo foram os custos de transporte de grãos (milho e soja) até a granja, o custo de transporte de suínos até o abatedouro e o custo de transporte de carcaça de suíno até o mercado consumidor. Definiu-se como mercado consumidor o próprio Estado de Goiás, o Distrito Federal e os municípios de São Paulo, Rio de Janeiro e Belo Horizonte. Além disso, determinou-se também as ofertas de milho e soja de cada microrregião do Estado de Goiás, e o consumo per capita nacional de carne suína. Considerou-se três cenários, envolvendo níveis distintos de consumo per capita, sendo um o atual e os outros dois determinados de acordo com as perspectivas do setor.
\end{abstract}

Palavras-chave: suinocultura, programação inteira, modelo de localização.

\begin{abstract}
The main purpose of this research work was to analyse the most efficient spatial distribution of pig production units in the state of Goiás. The model developed required a mixed integer programming structure. The factors considered in the model were: the grain transportation cost (corn and soybeans) from the source to the production unit, the cost of transporting the animals from the production unit to slaughterhouses and the carcass transportation cost from the slaughterhouse to retailers. The consumption market was spatialy defined as comprising the state of Goiás, the Distrito Federal and the counties of São Paulo, Rio de Janeiro and Belo Horizonte. Moreover, it was determined the supplies of corn and soybeans for each microregion in the state of Goiás and the national per capita pork consumption. Three scenarios, showing different per capita consumption levels, were considered. One of these is the current per capita consumption level and the two other were determined according to sector perspectives.
\end{abstract}

Keywords: pig production, integer programming, locational model. 


\section{Introdução}

$\mathrm{O}$ deslocamento da fronteira agrícola para o Centro-Oeste aumentou o interesse para implantação de projetos de produção moderna de suínos, conforme relata o BNDES (1995). Esse deslocamento visa a busca da proximidade de matéria-prima mais barata. Notadamente na segunda metade da década de 90 , grandes frigoríficos nacionais têm demonstrado grande interesse em se instalar na região, em especial no estado de Goiás.

O objetivo geral deste trabalho é estudar a maneira mais eficiente de se organizar as granjas de suínos bem como abatedouros, no Estado de Goiás, de modo a se obter a minimização dos custos de transporte de matéria-prima (no caso o milho e a soja), suínos e carcaças, de acordo com as previsões de safra, bem como diferentes tamanhos de granjas de suínos. Serão consideradas granjas de suínos de ciclo completo, isto é, da produção do leitão até o suíno terminado.

O problema em questão consiste assim na realização de um estudo onde seja possível identificar a melhor distribuição espacial da suinocultura e abatedouros no Estado de Goiás, bem como determinar quais seriam as regiões mais indicadas para o abastecimento de matéria-prima para a ração, de modo que sejam minimizados os custos de transporte e de aquisição de insumos, obtendo com isso uma redução nos custos de criação.

Dada a localização geográfica do Estado de Goiás e sua proximidade a grandes centros consumidores, identificam-se grandes vantagens no processamento e produção de alimentos naquele Estado, aproveitando a produção de matéria-prima agropecuária. Vale ressaltar que o fator terra é, também, outro provedor de vantagens, pois a mesma tem um custo menor, quando comparada com outros Estados, tais como São Paulo. Além do mais, o Estado de Goiás está localizado proximamente a diversos novos corredores de transporte, que no médio prazo poderão caracterizar uma excelente via de exportação, inclusive para os países do MERCOSUL.

\section{A Teoria da Localização}

A determinação sobre onde se produzir um determinado bem sempre representou uma preocupação, até mesmo para os economistas clássicos, mesmo que de uma forma superficial, conforme salienta Azzoni (1982). Um dos primeiros cientistas a estudar o problema de localização foi o alemão Von Thünen, no ano de 1826 (citado por Leme, 1982). Nesse trabalho, o autor procurou determinar a influência das cidades na produção agrícola, bem como a distribuição espacial das culturas, em função de seu valor, constituindo-se no que se convencionou de chamar "anéis de von Thünen".

O trabalho considerado como a gênese da teoria da localização foi desenvolvido pelo alemão Alfred Weber em 1909 (também citado por Leme, 1982). Ele determinou a localização da atividade industrial, através das forças de atração. Em seu estudo, Weber considerou uma área onde existia somente um único mercado consumidor e duas regiões fornecedoras de matéria-prima. As forças de atração, neste caso, foram representadas pelo custo de transporte, sendo que o equilíbrio de tais forças determinava a localização da atividade industrial. Após se determinar a localização, o mesmo procurava, através de isodapanas, verificar o efeito de outras forças de atração, como custo da mão-de-obra e aglomeração.

No modelo proposto por Weber, só se trabalhava com duas fontes de matéria-prima e uma região de demanda, constituindo, assim, um triângulo locacional. A partir deste triângulo, 
através das forças atrativas, poder-se-ia determinar a melhor localização da firma. Posteriormente, através de isodapanas, pode-se verificar a atuação de outras forças, como custo de mão-de-obra, que podem promover o deslocamento da firma para uma nova região.

Com o surgimento da programação linear, em meados da década de 40, em especial o modelo de transporte, puderam ser introduzidas situações mais complexas que a original. Pode-se então trabalhar com várias regiões de demanda, bem como com várias regiões de oferta de matéria-prima. Segundo Bressler \& King (1970), uma das vantagens de se trabalhar com modelos multirregionais consiste em se poder determinar, simultaneamente, o fluxo de produtos e os preços relativos de mercado.

De acordo com Amaro et al. (1973), o modelo tradicional de transporte, embora aprimorasse o modelo original, apresentava algumas limitações, conseqüência de suas pressuposições básicas, que estão relacionadas a seguir:

- considera um mercado em concorrência perfeita;

- não considera economia de escala no transporte;

- a tecnologia é considerada constante dentro da área de estudo;

- as ofertas e demandas de cada região são conhecidas;

- as variáveis observam relações lineares;

- não considera economia de escala no processamento.

Um grande avanço na determinação da localização foi alcançado a partir da utilização de novas formas de modelagem, como programação inteira/mista (mais especificamente com a utilização de variáveis binárias no modelo), programação dinâmica, e programação estocástica, que tornaram possível um maior relaxamento das pressuposições envolvidas no modelo tradicional de transporte.

\subsection{Aplicações em contextos agroindustriais}

Para Stollsteimer (1963), o problema de localização deve se ater não somente sobre a melhor localização, mas também sobre o número de firmas, tamanho, localização das fontes de matéria-prima e forma de distribuição do produto final, para que se possa programar os investimentos tanto na firma quanto em equipamentos. Tal autor desenvolveu um modelo básico para se determinar o número, tamanho e localização de packing-houses para pera na região noroeste da Califórnia, nos Estados Unidos. Dentro dessa concepção, King \& Logan (1964) desenvolveram uma metodologia para se determinar a localização, número e tamanho ótimo de abatedouros de bovinos para o estado da Califórnia, EUA. Em seu trabalho incluíram tanto os custos de transporte da matéria-prima quanto os custos de transporte do produto final. Já Baritelle \& Holland (1975) desenvolveram um procedimento matemático para a determinação de localização e tamanho ótimo de firmas, onde algumas variáveis foram incorporadas ao modelo, como custo da matéria-prima, estoque e carryover (estoque de passagem entre dois períodos agrícolas) e firmas com múltiplos produtos.

Usando modelo tradicional de transporte, Amaro et al. (1973), estudaram a forma eficiente de organizar o complexo das fábricas de processamento de laranja no Estado de São Paulo. Determinou-se quais seriam as regiões que iriam atender cada fábrica, inclusive identificando as áreas de conflitos, assim como as unidades passíveis de ampliação (mediante uma situação de excesso de oferta), ou ainda as regiões que permitissem a implantação de uma nova unidade. 
Kilmer et al. (1976), através do uso de programação dinâmica, estudaram a abertura de novos packing-houses, no estado da Flórida, EUA, uma vez que com o deslocamento da produção, observado nos últimos 50 anos, muitos desses packing-houses estavam ficando muito distantes da área de produção. Neste estudo, os autores procuram traçar uma programação para a abertura de novos packing-houses (estruturas onde se realizam as primeiras operações de classificação e limpeza de hortifrutis) assim como o fechamento de estruturas mais antigas. Visto que essa operação implicava custos adicionais, o objetivo do trabalho foi o de minimizar tais custos dentro do horizonte de estudo. Os autores procuraram ainda apresentar como seriam os ajustamentos de curto-prazo na localização. Foi ressaltado que os modelos estáticos de localização representavam uma solução ótima para o equilíbrio no longo-prazo, não havendo uma preocupação nos ajustamentos no curto-prazo. A pressuposição de oferta fixa foi relaxada: ela permaneceu fixa em um determinado período, mas observando níveis distintos em cada um dos períodos analisados.

Von Oppen (1976), utilizando modelo de equilíbrio espacial em conjunto com modelos de localização, determinou a localização, tamanho da área de mercado e o comércio interregional para a indústria de soja na Índia, aplicando importantes funções econômicas, tais como transporte de insumos e produtos, custos médios, ofertas e demandas regionais. Foi inicialmente determinada a localização das firmas por meio de um modelo de otimização, assim como o comércio inter-regional de insumos e produtos, com auxílio de um modelo de programação quadrática. Da solução ótima da localização se derivou o custo médio regional de processamento, o qual foi inserido no modelo de comércio inter-regional. Da solução ótima deste se derivaram as quantidades a serem processadas e distribuídas pelas firmas, que foram então inseridas no modelo de localização.

Almeida (1981) avaliou a viabilidade econômica de implantação e localização de unidades produtoras de farinha de milho integral e desengordurada a ser misturada com farinha de trigo. Para o caso da localização procurou-se minimizar os custos de transporte do milho e farinha, em conjunto com os custos de processamento, para se obter a localização ótima em função das restrições de escoamento do milho e da farinha, localização das unidades fabris bem como suas capacidades.

Brown \& Drynan (1986) ressaltam fato de o problema dos modelos básicos não considerarem variações tanto do lado da oferta quanto do lado da demanda, isto é, os bens e insumos são considerados perfeitamente inelásticos, com relação ao preço. Esta pressuposição bastante forte fez com que os mesmos autores optassem pela utilização de programação estocástica discreta. Trabalharam basicamente com variações estacionais, em conjunto com expectativas de safras (divididas em boa, média e ruim), para determinar a localização e tamanho ótimo de abatedouros de gado no Estado de Queensland, Austrália. Os autores chamam a atenção para as diferenças entre as soluções dos modelos básicos e aquelas obtidas pelo modelo por eles concebido.

Cruz (1990), através de sistema de redes não-capacitadas, determinou a localização e o tamanho que tornavam mais eficiente economicamente as unidades armazenadoras no Estado de Minas Gerais, através da minimização dos custos de transporte e instalação de novas unidades armazenadoras a granel. Trabalhando também com armazenamento de grãos, McCarl et al. (1985), determinaram a melhor organização de terminais de cargas, através da minimização dos custos de armazenagem e de transporte, tanto ao nível da fazenda quanto nos terminais.

Canziani (1991) estudou a localização de fábricas de suco de laranja concentrado no norte e noroeste do estado do Paraná, visando a minimização dos custos de coleta e reunião da produção, de processamento e de distribuição do produto final. $\mathrm{O}$ autor considerou, no 
modelo, economia de escala no transporte e processamento, projetando várias situações de oferta de matéria-prima.

Brown et al. (1996), utilizando modelo de programação linear, determinaram o número ótimo, bem como os locais para a indústria de tabaco na região da Virginia-EUA, baseandose nos atuais mercados e nas produções vigentes. Chegaram a conclusões sobre quais mercados deveriam ser fechados e quais deveriam ser consolidados.

Todos estes trabalhos citados atestam a grande diversidade de aplicações de modelos de localização desenvolvidas no contexto agroindustrial, com o auxílio de instrumental de programação matemática. Neste trabalho será utilizada programação mista, a mais adequada ao problema proposto, conforme será descrito a seguir.

\section{Desenvolvimento do Modelo de Localização}

Para o processo de localização de granjas e abatedouros no Estado de Goiás, é necessária a descrição das principais características do contexto envolvido, de forma a se ter ao final, uma clara visualização da base para o processo de formulação de um problema de localização.

O Estado de Goiás está dividido em 18 microrregiões homogêneas (ver Figura no Anexo I), que a princípio não apresentam nenhuma restrição quanto à instalação, tanto de granjas suinícolas quanto de abatedouros. Em todas estas regiões ocorre produção de grãos, no caso milho e soja, em quantidades distintas para cada uma delas, e que naturalmente podem ser transformadas em proteína animal. Aqui depara-se com a primeira parte do problema: será necessário realizar uma distribuição física de grãos, através do transporte das regiões que apresentam excesso de oferta para aquelas que apresentam excesso de demanda. Esta distribuição dos fluxos de grãos deve ser tal que os custos de transporte sejam minimizados. Para as regiões que se caracterizam como exportadoras, os grãos consumidos internamente, acrescidos daqueles que foram exportados, não devem ultrapassar sua capacidade de oferta. Para aquelas que se caracterizam como importadoras, a totalidade dos grãos consumidos internamente, adicionada à quantia que foi importada, deve ser inferior à demanda de grãos.

Para se dimensionar as demandas por grãos nas regiões, são considerados 15 tamanhos de suinoculturas, que poderão, ou não, ser instaladas nas regiões. A determinação de instalação de uma granja suinícola numa certa região envolve, de uma forma direta, os custos de implantação da mesma, além de fatores indiretos, associados à demanda por carne suína. Portanto, cada região apresentará um número de granjas de tamanhos distintos, a ser determinado pelo modelo, em função da proximidade desta com o mercado consumidor e do fornecimento de matéria-prima para a formulação de ração. Note-se assim que, ao se instalar uma granja suinícola numa região cria-se, além da demanda por grãos, uma oferta de animais para o abate.

Ao se definir a capacidade de oferta de suínos para cada região, parte-se, então, para a terceira parte do problema. Nesta etapa será considerado o sistema de transporte de animais, de sua origem até as regiões onde os mesmos serão abatidos. O objetivo, como no caso dos grãos, é minimizar os custos de transporte envolvidos, lembrando-se que a quantidade de suínos abatidos na própria região mais os exportáveis não devem superar a capacidade de oferta da região. Além disso, a quantidade de suínos abatidos internamente, mais as importações, não podem ser inferiores à capacidade de abate da região.

A demanda por suínos pode ser definida em função dos abatedouros que podem ser instalados nas diversas regiões. Aqui se irá considerar somente um tamanho de abatedouro, 
de 3000 animais-dia, que representa o tamanho médio das grandes empresas de embutidos. Tem-se, então, a quarta parte do problema a ser formulada, que representa a identificação das regiões onde serão implantados tais abatedouros. Por se tratar de abatedouros de grande porte, optou-se por limitar o número dos mesmos a um máximo de 3 unidades. Da mesma forma que para a granja, ao se instalar um abatedouro numa determinada região, cria-se naturalmente uma oferta de carcaças de suínos.

Finalmente, chega-se à situação em que se faz necessário abastecer os mercados consumidores através do transporte das carcaças, oriundas dos abatedouros. Os mercados consumidores serão representados pelas próprias regiões do Estado de Goiás, assim como pelos municípios de São Paulo, Belo Horizonte, Rio de Janeiro e Brasília, que se constituem em grandes mercados consumidores potenciais. $\mathrm{O}$ objetivo aqui é realizar tal distribuição de modo a se minimizar o custo de transporte das carcaças. Deve-se lembrar que as quantidades de carcaças que permanecem na região, mais as que serão transportadas, não devem superar a capacidade de oferta da região. Ao mesmo tempo, a quantidade que permanece na região, mais as que chegam de outras regiões, não devem ser inferiores à demanda da região. Notase que a demanda por carcaças será determinada através da população residente nas regiões e pelo consumo "per capita" nacional.

Portanto, de acordo com o exposto, o objetivo do modelo de localização será o de determinar os locais de instalação de suinocultura e abatedouros, de forma a se atender às diversas demandas, respeitando-se as várias ofertas, de forma a se ter ao final, de forma agregada, a minimização dos custos de transporte e de implantação de granjas e abatedouros.

\subsection{Modelagem}

\subsubsection{Especificação do Modelo}

O modelo a ser utilizado diz respeito à minimização de uma função objetivo representativa dos custos considerados para a localização da suinocultura, sujeita a uma série de restrições físicas e comportamentais.

As principais variáveis e parâmetros utilizados respeitam a seguinte nomenclatura:

$C_{i j}^{k}=$ custo de transporte de grãos $k$ da região i para a região $j$;

$G_{i j}^{k l}=$ quantidade de grão $k$ transportado da região $i$ para a granja de tamanho $l$ na região $j$;

$S_{i}^{k}=$ quantidade total de grãos $k$ disponível na região de produção $i$;

$D_{j}^{k l}=$ quantidade total demandada de grãos $k$ por todas as granjas $l$ instaladas na região $j$;

$K_{j}^{l}=$ valor associado à granja de tamanho $l$ na região $j$;

$F_{j}^{l}=$ variável binária associada à instalação da granja de tamanho $l$ na região $j$;

$C_{j i}=$ custo de transporte de suíno da região $j$ para a região $i$;

$S_{j i}^{l}=$ quantidade de suíno transportado da granja $l$ da região $j$ para a região $i$;

$B_{j}^{l}=$ capacidade de oferta das granjas de tamanho $l$ instaladas na região j;

$K_{i}=$ valor associado ao abatedouro na região $i$;

$A_{i}=$ variável binária associada à instalação do abatedouro na região $i$; 
$E_{i}=$ quantidade demandada de suíno pelo abatedouro que venha a ser instalado na região $i$;

$G_{i}=$ quantidade de carcaças de suínos ofertada pelo abatedouro a ser instalado na região $i$;

$C_{i m}=$ custo de transporte de carcaça de suíno da região $i$ para a região consumidora $m$;

$C S_{i m}=$ quantidade de carcaça de suíno transportada da região $i$ para a região $m$;

$D_{m}=$ demanda por carcaças de suínos da região $m$.

A especificação das equações e inequações pertinentes é apresentada a seguir.

\subsubsection{Função Objetivo}

Na função objetivo, representada pela equação (1), tem-se a função custo considerada para o problema de localização associado a este estudo.

$$
\begin{aligned}
& \operatorname{Min} \sum_{l=1}^{15} \sum_{k=1}^{2} \sum_{i=1}^{18} \sum_{j=1}^{18} C_{i j}^{k} G_{i j}^{k l} \\
& +\sum_{l=1}^{15} \sum_{j=1}^{18} K_{j}^{l} F_{j}^{l} \\
& +\sum_{l=1}^{15} \sum_{j=1}^{18} \sum_{i=1}^{18} C_{j i} S_{j i}^{l} \\
& +\sum_{i=1}^{18} K_{i} A_{i} \\
& +\sum_{i=1}^{18} \sum_{m=1}^{22} C_{i m} C S_{i m}
\end{aligned}
$$

Na parte (1a) tem-se o custo total de transporte de grãos, identificado pelo índice $k$, a partir das regiões de exportação, $i$, para as regiões de importação, $j$. O objetivo é atender todas as granjas de tamanho $l$. Note-se que são considerados 15 tamanhos possíveis de granjas, 2 tipos de grãos (milho e soja), 18 regiões de exportação e 18 regiões de importação (correspondentes às microrregiões de Goiás).

Na parte (1b) tem-se o custo de implantação de uma suinocultura de tamanho $l$, onde:

$K_{j}=$ representa o custo de uma granja suinícola de tamanho $l$ instalado na região $j$.

$F_{j}^{l}=$ variável binária, tipo zero ou um, associada à instalação de uma granja de tamanho $l$, na região $j .\left(F_{j}^{l} \in\{0,1\} \forall j=1, \ldots, 18 ; l=1, \ldots, 15\right)$

Na parte (1c) tem-se o custo total de transporte dos suínos produzidos pelas granjas de tamanho $l$, na região $j$, até os abatedouros presentes na região $i$.

Na parte (1d) tem-se o custo de implantação de um abatedouro, onde:

$K_{i}=$ representa o custo de um abatedouro instalado na região $i$.

$A_{i}=$ variável binária associada à instalação de um abatedouro. $\left(A_{i} \in\{0,1\} \forall i=1, \ldots, 18\right)$ 
Finalmente, na parte (1e), tem-se o custo total de distribuição de carcaças de suínos dos abatedouros das regiões $i$ até os mercados consumidores $m$. Note-se que foram considerados 22 mercados consumidores, representados pelas próprias 18 microrregiões de Goiás e pelos municípios de São Paulo, Belo Horizonte, Rio de Janeiro e Brasília.

\subsubsection{Restrições}

$\mathrm{Na}$ inequação (2) tem-se representada a restrição da capacidade de oferta de grãos da região $i$, onde a soma das quantidades de grãos $k$ que permanecem na região, adicionada às quantidades exportadas para as demais regiões, não deve exceder a capacidade de produção da própria região.

$$
\sum_{l=1}^{15} \sum_{j=1}^{18} G_{i j}^{k l} \leq S_{i}^{k} \quad \quad \mathrm{p} / \text { todo } k \text { e } i
$$

onde:

$\sum_{l=1}^{15} \sum_{j=1}^{18} G_{i j}^{k l}=\begin{aligned} & \text { quantidade total de grãos }(k) \text { transportada da região de produção } i \text { para todas as } \\ & \text { granjas }(l) \text { instaladas nas diversas regiões } j ;\end{aligned}$ $S_{i}^{k} \quad=$ quantidade total de grãos $(k)$ disponível na região de produção $i$.

$\mathrm{Na}$ inequação (3) tem-se o dimensionamento da demanda de grãos, onde a soma das quantidades consumidas na própria região, mais as quantidades que chegam de outras regiões, não devem ser inferiores à demanda desta região, representada pelas granjas instaladas na mesma.

$$
\sum_{i=1}^{18} G_{i j}^{k l}-F_{j}^{l} D_{j}^{k l} \geq 0 \quad \mathrm{p} / \text { todo } k, j \text { e } l
$$

onde:

$\sum_{i=1}^{18} G_{i j}^{k l}=\begin{aligned} & \text { quantidade total de grãos recebida de todas as regiões de produção } i \text {, para atender } \\ & \text { à totalidade de demanda das granjas }(l) \text { instaladas na região } j ;\end{aligned}$

$D_{j}^{k l} \quad=$ quantidade total demandada de grãos $(k)$ por todas as granjas $(l)$ instaladas na região $j$.

Pela inequação (4) é tratada a questão da capacidade de oferta de suínos da região $j$, onde a quantidade de suínos que permanece na região, mais a quantidade que é transportada para os abatedouros de outras regiões, não devem superar a capacidade de oferta total, representada pelas granjas que venham a ser instaladas na região.

$$
\sum_{l=1}^{15} \sum_{i=1}^{18} S_{j i}^{l}-F_{j}^{l} B_{j}^{l} \leq 0 \quad \mathrm{p} / \text { todo } j
$$

onde: $\sum_{l=1}^{15} \sum_{i=1}^{18} S_{j i}^{l}=\begin{aligned} & \text { quantidade de suínos transportados pelas diversas granjas } l \text { instaladas na região } j \\ & \text { e que irão abastecer os abatedouros instalados nas diversas regiões } i \text {; }\end{aligned}$

$B_{j}^{l} \quad=$ capacidade de oferta das granjas de tamanho $l$ instaladas na região $j$. 
Já através da inequação (5), é mensurada a demanda de animais, onde o número de suínos que permanecem na região mais as quantidades que chegam das demais não devem ser inferiores à demanda propriamente dita, representada pelos abatedouros que venham a ser instalados na região.

$$
\sum_{j=1}^{18} S_{j i}^{l}-A_{i} E_{i} \geq 0 \quad \mathrm{p} / \text { todo } i \text { e } l
$$

onde:

$\sum_{j=1}^{18} S_{j i}^{l}=$ quantidade de suínos transportados das diversas granjas $l$ instaladas nas diversas regiões $j$ para abastecer o abatedouro da região $i$;

$E_{i} \quad=$ quantidade demandada de suínos pelo abatedouro que venha a ser instalado na região $i$.

$\mathrm{Na}$ inequação (6) tem-se que a quantidade de carcaças transportadas dos abatedouros presentes na região $i$ para os mercados consumidores $m$ deve ser tal que não ultrapassem a capacidade total de oferta dos abatedouros, representada por aqueles já presentes na região e por aqueles que venham a ser instalados na região.

$$
\sum_{m=1}^{22} C S_{i m}-A_{i} G_{i} \leq 0 \quad \mathrm{p} / \text { todo } i
$$

onde:

$$
\begin{aligned}
\sum_{m=1}^{22} C S_{i m}= & \text { quantidade de carcaças de suíno transportadas da região de abate } i \text { até as regiões } \\
& \text { de demanda } m ; \\
G_{i} & = \\
& \text { quantidade de carcaças de suínos ofertada pelo abatedouro a ser instalado na } \\
& \text { região } i .
\end{aligned}
$$

$\mathrm{Na}$ inequação (7) representa-se a necessidade de carcaças de suínos do mercado consumidor, onde o total de carcaças que chegam neste mercado não deve ser inferior à sua demanda.

$$
\sum_{i=1}^{18} C S_{i m} \geq D_{m} \quad \mathrm{p} / \text { todo } m
$$

onde:

$$
\begin{array}{ll}
\sum_{i=1}^{18} C S_{i m}= & \text { quantidade de carcaças transportadas para a região de demanda } m, \text { oriunda de } \\
& \text { todas as regiões de abate } i ; \\
D_{m} & =\text { demanda por carcaças de suínos da região } m .
\end{array}
$$

Finalmente, na inequação (8) apresenta-se a limitação do número de abatedouros de grande porte (no caso, três) que poderão ser instalados nas regiões.

$$
\sum_{i=1}^{18} A_{i} \leq n
$$

onde: 
$A_{i}=$ a variável binária associada à instalação, ou não, de um abatedouro na região $j$.

$n=\left\{\begin{array}{l}1 \text { para o primeiro cenário, } \\ 2 \text { para o segundo cenário, e } \\ 3 \text { para o terceiro cenário. }\end{array}\right.$

Para a solução do modelo proposto foi utilizada a linguagem de otimização GAMS - General Algebraic Modeling System (Brooke et al., 1992), juntamente com o solver XA, em microcomputador com processador "Pentium II", $233 \mathrm{MHz}, 32 \mathrm{Mb}$ de memória RAM. Os tempos de processamento observados para os cenários 1,2 e 3 foram, respectivamente, de $4 \mathrm{~min} 02 \mathrm{~s}, 4 \mathrm{~min} 06 \mathrm{~s}$ e $5 \mathrm{~min} 03 \mathrm{~s}$.

\section{Resultados e Discussões}

\subsection{Apresentação dos cenários}

Para a determinação dos locais de instalação de suinoculturas, formulou-se três cenários. Estes cenários representam situações de consumo per capita de carne suína no Estado de Goiás, e quatro outros importantes mercados consumidores, representados pelo Distrito Federal e pelos municípios de Belo Horizonte, São Paulo e Rio de Janeiro.

O primeiro cenário representa um consumo de $8,0 \mathrm{~kg} / \mathrm{hab}$./ano, correspondente ao consumo médio nos últimos anos, em nível nacional. As demandas a serem atendidas foram limitadas aos Estado de Goiás e ao Distrito Federal. A este nível de consumo admitiu-se que as demais regiões consideradas já são atendidas por sua produção interna ou por outras regiões tradicionais na produção de suínos.

O segundo cenário foi caracterizado pelo consumo per capita de $10 \mathrm{~kg} / \mathrm{hab}$./ano. Além do mercado representado pelo próprio Estado de Goiás e Distrito Federal, foram atendidos, também, os municípios de Belo Horizonte, São Paulo e Rio de Janeiro. Estes mercados foram supridos por uma oferta correspondente à diferença entre o atual consumo realizado $\mathrm{e}$ o consumo considerado neste cenário, isto é, de $2,0 \mathrm{~kg} / \mathrm{hab}$./ano.

O terceiro e último cenário representa a situação mais otimista, onde o consumo per capita chegaria a $15 \mathrm{~kg} / \mathrm{hab}$./ano. Como no cenário anterior, os mercados atendidos foram os mesmos, mas os mercados de Belo Horizonte, São Paulo e Rio de Janeiro foram atendidos pelo hiato existente entre o atual consumo e o considerado neste cenário, no caso de 7,0 kg/hab./ano.

\subsection{Cenário 1 (consumo de $8 \mathrm{~kg} / \mathrm{hab} . / \mathrm{ano}$ )}

\subsubsection{Fluxo de grãos}

Observou-se neste cenário, para o caso do milho, que não houve a necessidade de transporte inter-regional, sendo que todas as regiões apresentaram excedentes de produção. Para o caso da soja, ocorreram dois casos de transporte inter-regional. Uma movimentação ocorreu da região de Pires do Rio para a região de Anápolis, e a outra da região de Palmeiras de Goiás para a região de Goiânia (Tabela 1). Com exceção feita às regiões importadoras, todas as demais apresentaram excedentes de produção. 
Tabela 1 - Fluxo de grãos (soja), ocorrido no primeiro cenário.

\begin{tabular}{lc}
\hline \multicolumn{1}{c}{ Centróides } & Exp./Imp \\
& $(+/-)$ \\
\hline Anápolis & $-549,26$ \\
Goiânia & $-140,90$ \\
Palmeiras de Goiás & 140,90 \\
Pires do Rio & 549,26 \\
\hline
\end{tabular}

Fonte: Dados da pesquisa.

\subsubsection{Escala de produção de suinocultura}

A economia de escala é um fenômeno comum a qualquer atividade econômica. Para o caso da suinocultura isto também pode ser observado. Dentre as possibilidades de instalação de granjas propostas pelo modelo, pode-se observar, através do Figura 1, uma tendência de instalação de granjas de tamanhos maiores (900 matrizes). A participação desse tamanho de granja foi de $13,85 \%$ no total, sugerido pelo modelo, em todo o Estado de Goiás.

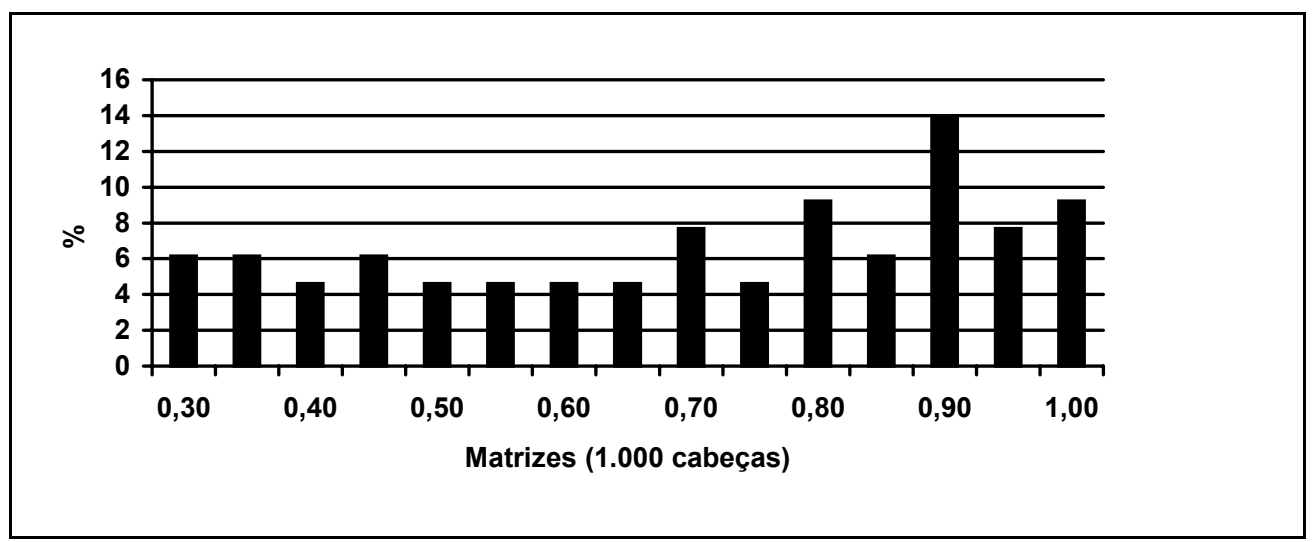

Fonte: Dados da pesquisa.

Figura 1 - Participação relativa das granjas para o primeiro cenário.

\subsubsection{Locais de instalação para abatedouro}

O abastecimento do mercado consumidor, em equivalente-carcaça, foi atendido pela instalação de um único abatedouro, suficiente para atendê-lo. Este mercado consumidor ficou limitado ao Estado de Goiás e ao Distrito Federal.

O local determinado para a instalação do abatedouro foi a microrregião de Luziânia. O abastecimento do abatedouro foi composto pela produção de 9 regiões. As principais regiões abastecedoras foram constituídas pelas regiões de Luziânia e Pires do Rio, sendo ambas responsáveis por mais de $43 \%$ da demanda do abatedouro. As outras regiões mais importantes no abastecimento são Goianésia e Goiânia, conforme mostra a Tabela 2. 
Tabela 2 - Regiões fornecedoras de suínos para o abatedouro, no cenário 1.

\begin{tabular}{lcc}
\hline \multicolumn{1}{c}{ Centróides } & Quantidade (t) & Participação relativa (\%) \\
\hline Luziânia & $22.530,07$ & 21,66 \\
Pires do Rio & $22.530,07$ & 21,66 \\
Goianésia & $18.486,21$ & 17,77 \\
Goiânia & $10.745,11$ & 10,33 \\
Outras & $29.733,54$ & 28,58 \\
\hline Total & 104.025 & 100 \\
\hline
\end{tabular}

Fonte: Dados da pesquisa.

A escolha da microrregião de Luziânia para a instalação de um abatedouro pode ser justificada pelo fato da mesma ser a mais próxima do principal mercado consumidor, representado pelo Distrito Federal, e ser também próxima, e de fácil acesso, a outro importante mercado consumidor, representado pela região de Goiânia. Na Tabela 3 são apresentados os principais centros consumidores.

Tabela 3 - Principais regiões abastecidas pelo abatedouro, no cenário 1.

\begin{tabular}{lccc}
\hline \multicolumn{1}{c}{ Região } & $\begin{array}{c}\text { Consumo } \\
(\mathrm{t})\end{array}$ & $\begin{array}{c}\text { Participação relativa do } \\
\text { consumo }(\%)\end{array}$ & $\begin{array}{c}\text { População } \\
(\text { hab. })\end{array}$ \\
\hline Excedente & $38.260,00$ & 45,97 & $4.782 .500^{*}$ \\
Distrito Federal & $12.808,75$ & 15,39 & 1.601 .094 \\
Goiânia & $10.161,97$ & 12,21 & 1.270 .146 \\
Entorno de Brasília & $3.780,70$ & 4,54 & 472.586 \\
Outras & $18.208,58$ & 21,89 & 2.276 .071 \\
\hline Total & 83.220 & 100 & 5.619 .999 \\
\hline
\end{tabular}

* Representa o equivalente populacional que poderia ser atendido pelo excedente

Fonte: Dados da pesquisa.

\subsection{Cenário 2 (consumo de $10 \mathrm{~kg} / \mathrm{hab} . / \mathrm{ano})$}

\subsubsection{Fluxo de grãos}

Neste cenário passa a ocorrer movimentação de milho. No caso da soja também existe a necessidade de se realizar movimentação de grãos. As regiões que realizaram importação são Anápolis e Goiânia. As que realizaram exportações são as de Palmeiras de Goiás e Pires do Rio. A região de Palmeiras de Goiás constituiu-se na região que realizou o maior volume de exportação, superando mais de 1.900 toneladas, atendendo à região de Goiânia (Tabela 4). 
Tabela 4 - Fluxo de grãos, milho e soja, para o segundo cenário.

\begin{tabular}{lrr} 
& \multicolumn{2}{c}{ Exp./Imp. (t) } \\
\cline { 2 - 3 } \multicolumn{1}{c}{ Centróides } & Soja & Milho \\
\cline { 2 - 3 } & & $(+/-)$ \\
\hline Goiás & $-1499,27$ & $-81,99$ \\
Anápolis & & \\
S.L.Montes Belos & 1499,27 & $-1999,12$ \\
Goiânia & & 1999,12 \\
Palmeiras de Goiás & & 81,99 \\
Pires do Rio & & \\
\hline
\end{tabular}

Fonte: Dados da pesquisa.

\subsubsection{Escala de produção de suinocultura}

A economia de escala de produção também se observa neste cenário, sendo predominante a utilização de granjas de tamanhos maiores. A granja de 900 matrizes apresenta uma participação de 8,96\%, seguida das de 600 matrizes, 800 matrizes e 1000 matrizes. Agregando-se por faixa de tamanhos, o grupo que vai de 800 a 1000 matrizes apresenta uma participação de $37,33 \%$, seguido dos grupos relativos às faixas de 550 a 750 matrizes e 300 a 500 matrizes, conforme mostra a Figura 2.

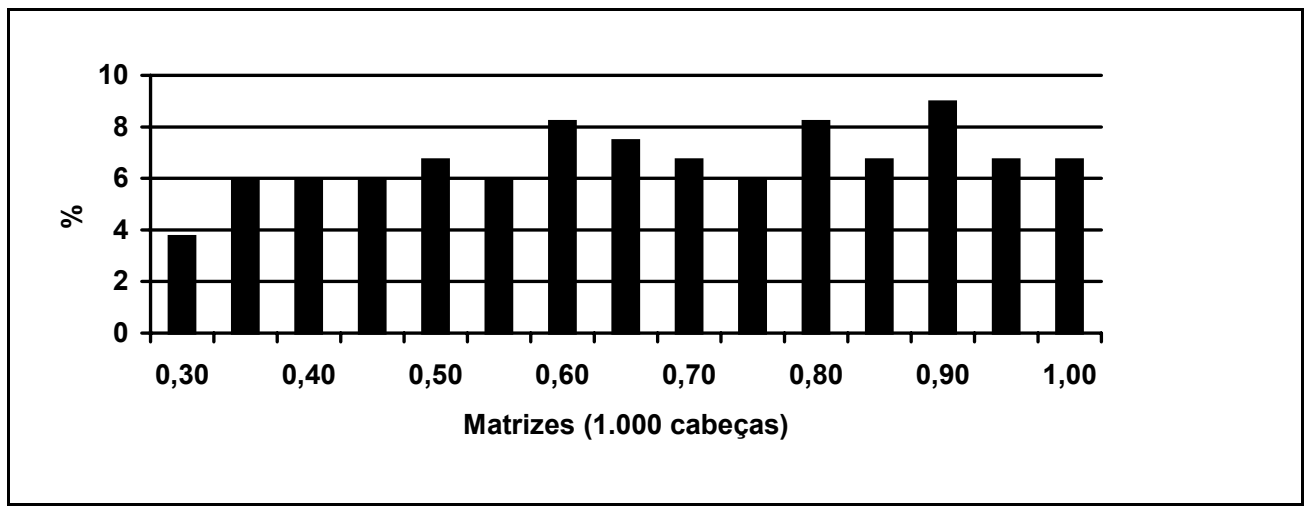

Fonte: Dados da pesquisa.

Figura 2 - Participação relativa das granjas no segundo cenário.

\subsubsection{Locais para instalação de abatedouros}

O abastecimento do mercado consumidor poderia ser realizado através da instalação de dois abatedouros, que foram mais do que suficientes para atendê-lo. Este mercado consumidor foi ampliado, em comparação ao cenário anterior, considerando-se agora os municípios de São Paulo, Belo Horizonte e Rio de Janeiro, além do Estado de Goiás e do Distrito Federal, que fazem parte de todos os cenários.

Luziânia e Itumbiara foram os locais escolhidos pelo modelo para a instalação dos abatedouros. $\mathrm{O}$ abastecimento dos abatedouros foi obtido com as produções de 13 regiões. 
As principais regiões abastecedoras de Luziânia foram a própria região de Luziânia, além de Pires do Rio e Catalão, responsáveis por mais de $61 \%$ da demanda do abatedouro. O abatedouro de Itumbiara foi atendido pelas produções da própria Itumbiara, além de Rio Verde, Palmeiras de Goiás e Quirinópolis, totalizando 85,30\% da demanda deste abatedouro. Neste cenário observa-se uma pequena competição pela produção suinícola de Catalão, sendo que $99,22 \%$ da produção deste município abastece o abatedouro de Luziânia e 0,78\% o abatedouro de Itumbiara. As regiões produtoras de suínos e os respectivos abatedouros que as mesmas atendem podem ser melhor observados na Tabela 5.

Tabela 5 - Regiões fornecedoras de suínos para o abatedouro, no cenário 2.

\begin{tabular}{lcccc}
\hline \multirow{2}{*}{ Centróides } & \multicolumn{2}{c}{ Luziânia } & \multicolumn{2}{c}{ Itumbiara } \\
\cline { 2 - 5 } & $\begin{array}{c}\text { Quantidade } \\
(\mathrm{t})\end{array}$ & $\begin{array}{c}\text { Participação } \\
\text { relativa (\%) }\end{array}$ & $\begin{array}{c}\text { Quantidade } \\
(\mathrm{t})\end{array}$ & $\begin{array}{c}\text { Participação } \\
\text { relativa (\%) }\end{array}$ \\
\hline Entorno de Brasília & 21836,84 & 20,99 & & \\
Pires do Rio & 22530,07 & 21,66 & & 21,66 \\
Itumbiara & & & 22530,07 & 21,66 \\
Rio Verde & & & 22530,07 & 20,99 \\
Palmeiras de Goiás & & & 21836,84 & 20,99 \\
Quirinópolis & 19832,63 & 19,07 & 21836,84 & 0,15 \\
Catalão & 18486,21 & 17,77 & 155,59 & 14,55 \\
Goianésia & 21339,25 & 20,51 & 15135,59 & 100 \\
Outras & 104,025 & 100 & 104.025 & \\
\hline Total & & & & \\
\hline
\end{tabular}

Fonte: Dados da pesquisa.

A justificativa para a escolha destas regiões para a instalação dos abatedouros pode ser explicada pelo fato das mesmas se localizarem mais próximas dos principais mercados consumidores. $\mathrm{O}$ abatedouro de Luziânia atende ao mercado do Distrito Federal, ficando para o abatedouro de Itumbiara a incumbência de atender aos mercados de São Paulo, Rio de Janeiro e Goiânia, três importantes mercados. Na Tabela 6 pode-se observar os principais centros consumidores, assim como a distribuição das carcaças efetuada pelos abatedouros.

Tabela 6 - Principais regiões abastecidas pelos abatedouros, no cenário 2.

\begin{tabular}{lcccc}
\hline & \multicolumn{2}{c}{ Luziânia } & \multicolumn{2}{c}{ Itumbiara } \\
\cline { 2 - 5 } & $\begin{array}{c}\text { Quantidade } \\
(\mathrm{t})\end{array}$ & $\begin{array}{c}\text { Participação } \\
\text { relativa (\%) }\end{array}$ & $\begin{array}{c}\text { Quantidade } \\
(\mathrm{t})\end{array}$ & $\begin{array}{c}\text { Participação } \\
\text { relativa (\%) }\end{array}$ \\
\hline São Paulo & & & 19292,37 & 23,18 \\
Rio de Janeiro & & & 10961,53 & 13,17 \\
Distrito Federal & 16010,94 & 19,24 & & 12702,48 \\
Goiânia & & & & 15,28 \\
Anápolis & 4019,19 & 5,68 & & \\
Luziânia & 4725,85 & 5,68 & 4040,32 & 4,85 \\
Belo Horizonte & & & 8848,99 & 10,63 \\
Outras & 9892,54 & 11,89 & 27374,33 & 32,89 \\
Excedente & 48571,48 & 58,37 & 83.220 & 100 \\
\hline Total & 83.220 & 100 & & \\
\hline
\end{tabular}

Fonte: Dados da pesquisa. 
A instalação dos abatedouros no porte em que foi proposto provocará um excedente superior a 75 mil toneladas, o que representa para este cenário a opção por dois abatedouros de menor capacidade, ou por um único abatedouro de maior capacidade. Por outro lado poder-se-ia, também, atender regiões que se localizam além dos limites do Estado, transformando o Estado de Goiás num grande exportador de carne suína.

\subsection{Cenário 3 (consumo de $15 \mathrm{~kg} / \mathrm{hab} . / \mathrm{ano}$ )}

\subsubsection{Fluxo de grãos}

Neste cenário observa-se a ocorrência de transporte de milho e soja, como no cenário anterior. Para o caso da soja, a principal região exportadora foi a de Palmeiras de Goiás, superando 27 mil toneladas, e a principal importadora foi a de S. L. Montes Belos, com um volume importado superior a 10 mil toneladas (Tabela 7).

Tabela 7 - Fluxo de grãos, milho e soja, ocorrido no terceiro cenário.

\begin{tabular}{lrr}
\hline & \multicolumn{2}{c}{$\begin{array}{c}\text { Exp./Imp. (t) } \\
\text { Centróides }\end{array}$} \\
\cline { 2 - 3 } & \multicolumn{1}{c}{ Milho } & \multicolumn{1}{c}{ Soja } \\
\hline Crixás & $-1714,64$ & $-3435,29$ \\
Goiás & & 1563,68 \\
Aragarças & $-813,18$ & $-1107,06$ \\
Porangatu & $-543,45$ & 3435,29 \\
Campos Belos & 1263,69 & \\
Goianésia & 271,68 & $-1970,06$ \\
Anápolis & 543,45 & $-8726,46$ \\
Iporá & $-4511,67$ & $-5163,95$ \\
S.L.Montes Belos & 5324,85 & $-10105,80$ \\
Goiânia & 1442,96 & $-6545,46$ \\
Posse & $-1263,69$ & 22,18 \\
Luziânia & & 27340,56 \\
P. de Goiás & & 4692,37 \\
Pires do Rio & & \\
\hline
\end{tabular}

Fonte: Dados da pesquisa.

\subsubsection{Escala de produção de suinocultura}

Dentre as possibilidades de instalação de granjas que foram propostas, observa-se, através do Figura 3, uma tendência de se instalar granjas de tamanhos maiores (800 e 900 matrizes). A participação de tal tamanho de granja foi de $8,33 \%$ no total instalado em todo o Estado de Goiás. Agrupando-se as granjas em três grandes classes de tamanho, as cinco menores, as cinco medianas e as cinco maiores, a participação deste último grupo predomina, com $37,24 \%$ de participação, vindo os grupos menores e medianos logo a seguir. 


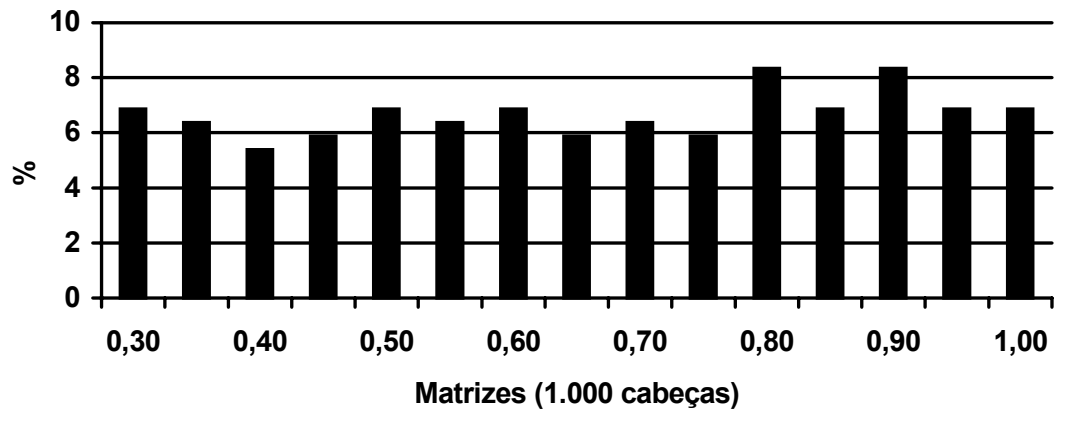

Fonte: Dados da pesquisa.

Figura 3 - Participação relativa das granjas no terceiro cenário.

\subsubsection{Locais de instalação para abatedouros}

Neste cenário, o abastecimento do mercado consumidor foi atendido pela instalação de três abatedouros. Os locais determinados para a instalação dos abatedouros foram as microrregiões de Itumbiara, Pires do Rio e Catalão.

O abastecimento destes abatedouros foi alcançado pela produção de 18 regiões, conforme mostra a Tabela 8. As principais regiões abastecedoras de Itumbiara foram a própria Itumbiara, Rio Verde, Quirinópolis e Goiânia, totalizando mais de $86 \%$ da necessidade deste abatedouro. $\mathrm{O}$ abatedouro de Pires do Rio apresentou como principais regiões abastecedoras os municípios de Luziânia, Pires do Rio, Anápolis e Porangatu, que atenderam a mais de $84 \%$ da capacidade do abatedouro. O abatedouro de Catalão foi atendido pelo próprio município e por Palmeiras de Goiás, S.L. Montes Belos e Goianésia.

Tabela 8 - Regiões fornecedoras de suínos para o abatedouro, cenário 3.

\begin{tabular}{|c|c|c|c|c|c|c|}
\hline & \multicolumn{2}{|c|}{ Itumbiara } & \multicolumn{2}{|c|}{ Pires do Rio } & \multicolumn{2}{|c|}{ Catalão } \\
\hline & Quantidade & $\%$ & Quantidade & $\%$ & Quantidade & $\%$ \\
\hline Itumbiara & $22.530,07$ & 21,66 & & & & \\
\hline Rio Verde & $22.530,07$ & 21,66 & & & & \\
\hline Quirinópolis & $22.530,07$ & 21,66 & & & & \\
\hline Goiânia & $22.530,07$ & 21,66 & & & & \\
\hline Luziânia & & & $22.530,07$ & 21,66 & & \\
\hline Pires do Rio & & & $21.721,30$ & 20,88 & & \\
\hline Anápolis & & & $22.530,07$ & 21,66 & & \\
\hline Catalão & & & & & $22.530,07$ & 21,66 \\
\hline Palmeiras de Goiás & & & & & $22.530,07$ & 21,66 \\
\hline S.L.Montes Belos & & & & & $20.219,29$ & 19,44 \\
\hline Porangatu & & & $21.605,76$ & 20,77 & & \\
\hline Goianésia & 944,36 & 0,91 & $11.127,16$ & 10,70 & $10.438,55$ & 10,03 \\
\hline Outros & 12960,36 & 12,46 & 4510,64 & 4,34 & $28.307,02$ & 27,21 \\
\hline Total & 104.025 & 100 & 104.025 & 100 & 104.025 & 100 \\
\hline
\end{tabular}

Fonte: Dados da pesquisa. 
Nota-se que neste cenário ocorre a disputa por todos os abatedouros pela produção de Goianésia, que fornece $4,19 \%$ de sua produção para Itumbiara, 49,43\% para Pires do Rio e $46,38 \%$ para o abatedouro de Catalão.

A escolha de tais regiões para a instalação dos abatedouros pode ser justificada também pelo fato de se localizarem próximas dos principais mercados consumidores, representados pelo Distrito Federal, São Paulo, Rio de Janeiro e Belo Horizonte. Na Tabela 9 são apresentados os principais centros consumidores abastecidos pelos abatedouros.

Tabela 9 - Principais regiões abastecida pelos abatedouros, no cenário 3.

\begin{tabular}{lccrrrr}
\hline & \multicolumn{2}{c}{ Itumbiara } & \multicolumn{2}{c}{ Pires do Rio } & \multicolumn{2}{c}{ Catalão } \\
\cline { 2 - 7 } & Quantidade & \multicolumn{1}{c}{$\%$} & Quantidade & $\%$ & Quantidade & $\%$ \\
\hline Rio Verde & 4307,38 & 5,18 & & & & \\
Porangatu & & & 3606,88 & 4,33 & & \\
Goiânia & & & 19053,69 & 22,90 & & \\
Rio de Janeiro & 38365,36 & 46,10 & & & & \\
Belo Horizonte & 14141,12 & 16,99 & & & 14130,25 & 28,86 \\
Distrito Federal & 9886,16 & 11,88 & & & 1566,45 & \\
Catalão & & & & & 67523,30 & 81,14 \\
São Paulo & & & & & \\
Anápolis & 1339,69 & 1,61 & & & & \\
Palmeiras de Goiás & 6145,06 & 7,38 & 18486,90 & 22,21 & & \\
Outros & 9035,23 & 10,86 & 36295,04 & 43,61 & & \\
Excedente & 83220 & 100 & 83220 & 100 & 83220 & 100 \\
\hline Total & & & & & \\
\hline
\end{tabular}

Fonte: Dados da pesquisa.

A instalação dos abatedouros no porte em que foi proposto provocará um excedente superior a 36 mil toneladas, referentes à produção do abatedouro de Pires do Rio, além de 9 mil no abatedouro de Itumbiara. Poder-se-ia assim a optar por abatedouros de menores capacidades para estes municípios, ou ainda considerar a alternativa do Estado se tornar um exportador de carne suína, visando atender a outros Estados.

\section{Conclusões}

A Região Sul tem apresentado uma série de limitações à expansão da suinocultura, sendo o restrito espaço físico um dos problemas para a efetivação dessa expansão. Outro fator de fundamental importância está relacionado aos custos de produção de insumos, basicamente milho e soja, para a suinocultura. Neste aspecto o Centro-Oeste tem-se caracterizado como uma grande fronteira para a expansão da suinocultura, sendo considerado como um grande celeiro agrícola do País. O Estado de Goiás destaca-se neste cenário pela sua característica geográfica, ocupando uma posição eqüidistante dos principais centros consumidores brasileiros.

Nesse contexto, é interessante o estudo da distribuição espacial da suinocultura e abatedouros dentro do Estado, de modo a se obter a minimização dos custos de transporte envolvidos. A teoria da localização desenvolvida por Weber e aprimorada através da programação matemática e de uma série de avanços computacionais constituiu-se num ferramental bastante apropriado a este estudo. 
O estudo de localização desenvolvido priorizou três cenários, todos relacionados ao consumo per capita de carne suína, em equivalente-carcaça. Foram considerados, também, grandes centros consumidores localizados além dos limites do Estado, tais como os municípios de São Paulo, Belo Horizonte, Rio de Janeiro e o Distrito Federal.

De acordo com os resultados apresentados, observou-se para todos os cenários uma tendência à implantação de granjas de grande porte, o que possibilitaria uma série de economias de escala. A localização das mesmas obedeceu à tendência de localização próxima ao abatedouro, o que seria uma forma de se minimizar os custos de transporte de animais. Por outro lado, observou-se, no cenário 1, que todas as microrregiões apresentam milho suficiente para atender à demanda projetada, ocorrendo somente nos cenários 2 e 3 a necessidade de transporte daquele grão. Para o caso da soja sempre foi necessária a movimentação entre as regiões. De uma forma geral, a produção de grãos sempre excedeu às necessidades de consumo.

A mudança de locais de instalação das granjas, para todos os cenários, seria viável, com algumas vantagens, nos locais onde houve a instalação de abatedouros. Isto sugere que os locais onde ocorressem a instalação de abatedouros viessem a se transformar em locais de grande concentração de granjas de suínos. Tal fato pode ser verificado na Região Sul do País, onde a grande concentração de suinocultura se dá exatamente onde estão localizadas as grandes empresas do ramo de abate de suínos.

Para todos os cenários observou-se que à medida que o consumo per capita aumentasse haveria uma tendência de se instalar um abatedouro mais ao sul do Estado, tendo-se em vista a responsabilidade pelo atendimento ao principal mercado consumidor brasileiro, que é São Paulo, em função da sua grande população, e também por se localizar numa saída para outros importantes mercados, como Belo Horizonte e Rio de Janeiro.

Um aspecto importante do trabalho foi a caracterização da região sul do Estado de Goiás como sendo de grande potencial para a produção de proteína animal, a partir da proteína vegetal, uma vez que se verificou uma forte tendência em se concentrar nesta região a instalação de granjas e abatedouros.

A implantação de granjas de suínos e abatedouros no Estado de Goiás já pode ser considerada como um fato concreto, através do interesse e confirmação de algumas empresas de grande porte em se instalar na região, principalmente na área de Rio Verde.

De qualquer maneira, urge que extensões do modelo de localização sejam formuladas, envolvendo, por exemplo, fatores não tratados diretamente neste estudo.

Um aspecto importante a ser considerado na localização diz respeito às vantagens que as empresas podem desfrutar nas chamadas "guerras fiscais", tais como isenção de impostos, doação de terrenos e outros benefícios. Outro fator importante a ser tratado em estudos futuros deve dar conta de um maior detalhamento da definição das áreas de interesse, pois a caracterização de um Estado da Federação como um todo talvez não seja a melhor alternativa a ser considerada. Assim sendo, a caracterização dos custos por região é recomendável não somente em Goiás mas em estados vizinhos.

Finalmente, para estudos de localização que envolvem produtos de origem agropecuária, deve-se considerar sua competitividade em nível internacional, uma vez que o país se destaca pelo seu grande potencial agro-exportador. Para tais estudos, onde a exportação esteja sendo considerada, será preciso levar em conta outros tipos de modais de transporte, tais como as ferrovias, assim como os custos de movimentação em diferentes portos. 


\section{Referências Bibliográficas}

(1) Almeida, L.A.S.B. (1981). Viabilidade econômica e localização de unidade produtora de farinha de milho para utilização em mistura com o trigo no estado de São Paulo, Piracicaba. 159p. Dissertação (Mestrado) - Escola Superior de Agricultura "Luiz de Queiroz", Universidade de São Paulo.

(2) Amaro, A.A. et al. (1973). Desenvolvimento da citricultura e localização de novas indústrias para o processamento no estado de São Paulo. Série Pesquisa, Departamento de Economia e Sociologia Rural. ESALQ, n.22, 1-78.

(3) Azzoni, C.R. (1982). Teoria da localização: uma análise crítica. São Paulo: IPE/USP, 200p.

(4) Baritelle, L.J. \& Holland, D.W. (1975). Optimum plant size and location: a case for separable programming. Agricultural Economics Research, 27, n.3/4, 73-84, Jul/Out 1975.

(5) BNDES (1995). Área de operações industriais 1 - AO1 gerência setorial de agroindústria - Suinocultura. Informe setorial. n.6, Dez 1995.

(6) Bressler, R.G. \& King, R.A. (1970). Markets, prices, and interregional trade. Nova York: Jonh Wiley, 426p.

(7) Brooke, A.; Kendrick, D. \& Meeraus, A. (1992). GAMS: A User's Guide, Release 2.25. Redwood City, CA. The Scientific Press, 289p.

(8) Brown, E.; Fathi, Y. \& Sowell, R. (1996). Linear programming applied to facility location problem. Applied engineering in agriculture, 12(1), 105-110. Resumo em CAB abstracts on CD-ROM, 1996-98/7.

(9) Brown, C.G. \& Drynan, R.G. (1986). Plant location analysis using discrete stochastic programming. The Australian Journal of Agricultural Economics, 30(1), 1-22, Abr. 1986.

(10) Canziani, J.R.F. (1991). Simulação sobre a implantação da indústria de suco concentrado de laranja no estado do Paraná. Piracicaba. 111p. Dissertação (Mestrado) Escola Superior de Agricultura “Luiz de Queiroz”, Universidade de São Paulo.

(11) Cruz, J.C. de F. (1990). Eficiência locacional e dimensões econômicas de unidades armazenadoras no estado de Minas Gerais. Viçosa. 97p. Dissertação (Mestrado) Universidade Federal de Viçosa.

(12) Kilmer, R.L.; Spreen, T. \& Tilley, D.S. (1976). A dynamic plant location model: the east Florida fresh citrus packing industry. American Journal of Agricultural Economics, 65(4), 730-37.

(13) King, G.A. \& Logan, S.H. (1964). Optimum location, number and size of processing plants with raw product and final product shipments. Journal of Farm Economics, 46(1), 94-108.

(14) Leme, R.A.S. (1982). Contribuição à teoria da localização industrial. IPE/USP, 397p.

(15) McCarl, B.A.; Hilger, D.A. \& Uhrig J.W. (1985). Grain subterminal facility location: a mixed-interger programming model. In: KOO, W.W. \& LARSON, D.W., Transportation models for agricultural products. Boulder: Westview Press, 13-33. 
(16) Stollsteimer, J.F. (1963). A working model for plant numbers and location. Journal of Farm Economics, 45(3), 631-45, Ago. 1963.

(17) Von Oppen, M. \& Scott, J.T. (1976). A spatial equilibrium model for plant location and interregional trade. American Journal of Agricultural Economics, 58(3), 437-45.

\section{Anexo I}

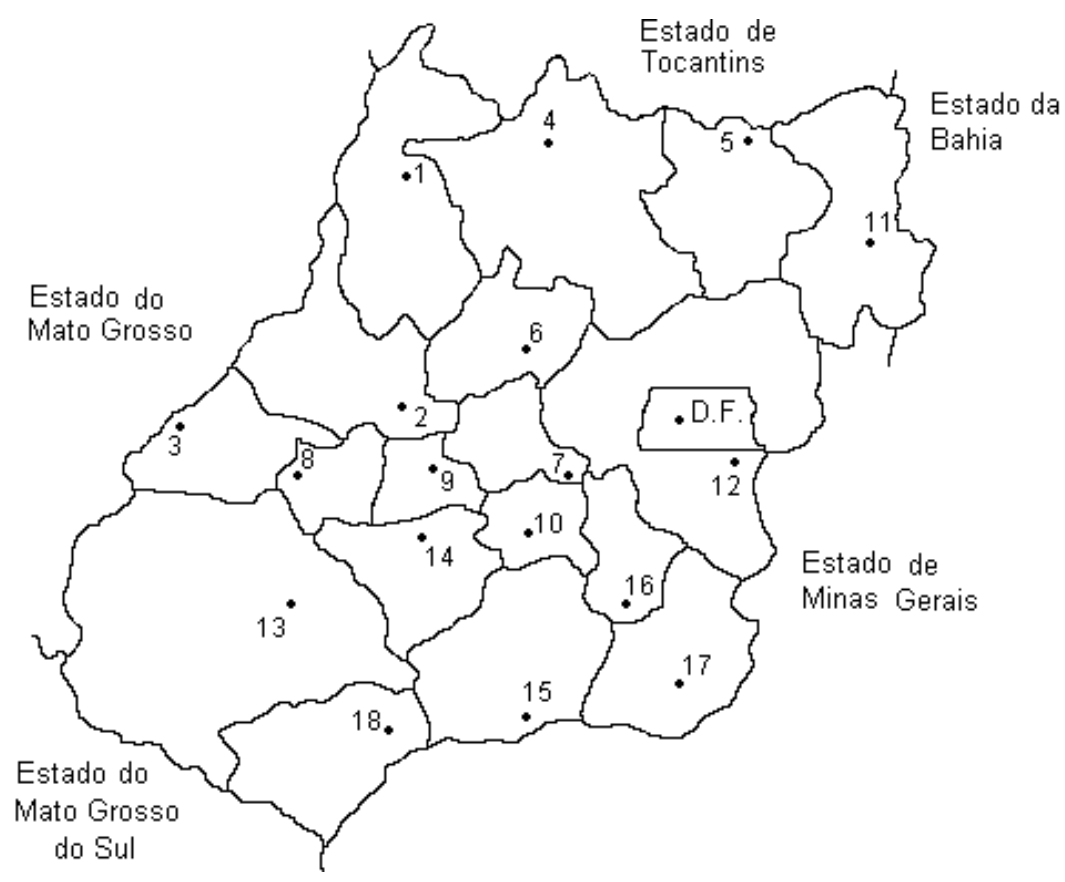

\begin{tabular}{|lll|}
\hline & MICRORREGIÕES \\
1 - São Miguel do Araguaia & 7 - Anápolis & $13-$ Sudoeste de Goiás \\
2 - Rio Vermelho & 8 - Iporá & $14-$ Vale do Rio dos Bois \\
3 - Aragarças & 9 - Anicuns & $15-$ Meia Ponte \\
4 - Porangatu & 10 - Goiânia & $16-$ Pires do Rio \\
5 - Chapada dos Veadeiros & 11 - Vão do Paraná & 17 - Catalão \\
6 - Ceres & 12 - Entorno de Brasília & $18-$ Quirinópolis \\
\hline
\end{tabular}

Figura - Mapa de Goiás com suas respectivas microrregiões. 